\title{
Interview with Tony Bates on the Aspects and Prospects of Online Learning
}

\author{
Ali Simsek \\ Anadolu University, Turkey
}

Tony Bates is a world-known expert on distance education. He has published extensively on both traditional and contemporary distance learning practices. Besides teaching courses and delivering seminars in the area of distance education, he has also provided consultancy with a number of institutions around the world. These include both formal and non-formal education settings such as governments, universities, corporations, and projects.

Professor Bates has recently been working in the field of online learning. He has published several milestone articles in this area. His articles shed light on important issues of online learning. He is one of the living legends who have witnessed how distance education has evolved into online learning over the year so that we decided to interview him on this topic. Because he was in Canada and I was in Turkey, we conducted the interview in several rounds of e-mail exchanges but it worked very well.

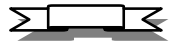

\section{What are the driving forces that have made online learning popular?}

Several factors have played important roles in this process. Some of them have been related to developments in technology and some have been about shifts in educational paradigms. These include but not limited to:

- Students' increasing access to, experience and comfort with technology

- Need for flexible delivery of programs to students who are often working as well as studying

- Online learning fits good pedagogy of active learning and collaborative learning

- Overcrowding of conventional classrooms drives students to online learning

What is the extent that online learning has been implemented in educational systems around the world?

In fact, it is very high in the United States and Canada. In the USA over $90 \%$ of higher education institutions use a learning management system; 11 million students (40\%) take at least some of their classes online. Online enrollments have been growing between $14-20 \%$ per annum compared with growth of $2 \%$ per annum for classroom-based programs. High usage has also been reported in the United Kingdom, Australia, New Zealand and Northern Europe. Regarding the other parts of the world; it is also growing rapidly in China and India, where although the percentage using online learning is low, the actual numbers are high. Brazil has extensive 
online learning in its school systems. Mobile learning is spreading in Africa, although numbers are still small.

Online practices are not constrained to universities. In Canada, for example, many school systems use online learning in Grades 10, 11 and 12 (older secondary students) as a supplement or option to classroom teaching. It is expected that other countries will soon follow Canada in this area.

\section{Why some of the online learning initiatives have failed?}

The main reason is poor pedagogy: Taking a classroom model and trying to take it online (for instance using video recordings of lectures, rather than designing interactive online materials). Another reason is too many students per instructor. The optimum class size for online learning is between 20-30 students per instructor, although larger numbers can be handled with really good course design. Online students need to know that an instructor is 'present' and available when needed.

\section{What are the most common delivery formats of online learning?}

The main format is still the fully online course using a learning management system such as Blackboard or Moodle. Students will need a computer and Internet access. Mobile learning is the future, but because there are no common technical standards between different phones, there is a shortage of good educational applications to date. This will change around 2012, when HTML5 enables a common standard for web browsers on mobile phones.

\section{How should online learning systems be structured in formal and non-formal educational settings?}

Over the last 15 years there has been a more or less 'standard' model for formal educational settings, based on a teacher-controlled learning management system; which organizes content, provides forums for discussions, and online tests. 'Good' design has clearly defined learning outcomes, short 'modules' of learning activities, continuous assessment (e.g. test or essays at least once a month), regular feedback from the instructor, and often group learning activities, such as discussion forums or joint projects.

However, with the development of web 2.0 tools such as blogs, social software such as Facebook, search engines such as Google, and e-portfolios which enable students to create and save their work and make it 'public', there is an increasing move to new course designs built around open content, collaborative learning, and learner-generated content. This is strongest at the moment in non-formal learning but is beginning to penetrate into formal learning as well.

\section{What are the most crucial elements of infrastructure for an online learning system?}

There are two critical elements of infrastructure: Technological and human.

Reliable and well-supported technology is an essential component of successful online learning. At the point where the student is working, medium speed Internet access is essential, with at least 2 megabits per second ideally, although it can work with slightly slower speeds. A standard computer with a keyboard and good size screen is also important for long periods of 
online study, although mobile devices are useful for short bursts of learning. Reliability is particularly important. This means that Internet connections should be stable, that the learning management system is always accessible, and if there is a technical problem, it is quickly and easily resolved. Many online programs in developing countries or covering rural areas manage at less than this standard, but only because the students show tremendous determination and persistence.

The human infrastructure is also important. There should be 24 hour, seven days a week technical support available (this may mean outsourcing to a shared service), good online administrative support (staff who know the 'rules' for online admission, course registrations) who respond quickly by e-mail or phone, good web-based information about the online courses and programs, that informs students about what is involved in online learning (hours per week of study, etc.), and good support from instructors during a course.

\section{Which is more dominant in designing online learning, technology or pedagogy?}

Both are important. As we have seen above, if the technology doesn't work, the students can't learn. However, the pedagogy is equally important. Just loading up huge amounts of content for students to memorize is not only ineffective in online learning, it is also poor teaching in that students these days need to know how to find, analyze, and apply information. The teaching needs to be designed to encourage and support such learning.

\section{What should be the roles of instructors during online learning?}

There are often two kinds of instructors in online learning: The main subject expert (faculty in a university) and an adjunct or contract instructor. In an ideal situation, the learning objectives, course content, and assessment of students will be decided by the main instructor. However, hired (and preferably trained) contract instructors will assist with the delivery of the course. This will involve being available to answer questions from students, moderate online discussions, manage group projects, and mark student assessments.

The best courses I have worked with also have instructional designers, who are experts in online teaching and advice/assist the subject expert, and web designers. Thus, the course is offered by a team of specialists working together.

\section{What are the most important expectations from learners attending an online learning program?}

- Good quality and relevant content, with clear learning objectives

- Prompt and helpful feedback from both instructors and the administration

- Assessments that test what the course sets out to achieve in terms of learning outcomes.

\section{How much of the website for an online course should be open to the public?}

- The learning objectives,

- A summary of course content (what the course is about)

- List of main readings/references

- Names and positions of instructors teaching on the program 
- Course schedule (when assignments are due, the breakdown of content)

- Requirements of students (e.g., participation in online forums, work in a group)

- Institutional policies regarding online behavior

- Examples of content

- Examples of student work from previous years (with permission of the students who did the work).

\section{What are your thoughts about open courseware?}

Open courseware needs to be specially designed for online learning. Taking unedited 50 minute video recordings of classroom lectures and making them 'open' is fine for non-formal learning and for helping instructors prepare for a course but is unhelpful for students in a structured course.

There is too much emphasis on the supply of open content by elite academic institutions and not enough on its design and use. Open content needs to be designed in short self-contained chunks ranging from 4 to 15 minutes of 'study time', with activities built around the content that link to broader course objectives. The 'best' open content is usually not academic material from face-to-face teaching but materials created for research, entertainment or other purposes that can be used as resource material for study purposes; however, that means embedding it in a broader instructional strategy.

Its real value will appear when courses are designed around learner-generated content, where students find the content for a course on the web, re-mash and re-edit it to demonstrate their learning. We are not there yet though in most institutions.

\section{What is the rationale of password requirement for an online course?}

Students have a right to privacy when learning, and instructors also need to feel that they are not open to censorship or attacks on their academic freedom. Both instructors and students need to be able to make mistakes and learn from those mistakes, otherwise there will be no creativity or innovation resulting from the teaching. Lastly, the teaching and learning needs to be focused and not distracted by spam, rude or ill-informed interventions from the general public.

Having said that, I do believe we should be opening up our courses to invited or approved guests, such as previous students, those thinking of taking the course in the future, people working in areas relevant to the course content, even employers.

\section{What is the ideal size or the learners/instructor ratio for an online course?}

This will depend very much on the design of the course and the learning objectives. The more creativity and individualization of learning, the lower the student numbers per instructor. Thus, an undergraduate course that teaches mathematics with an emphasis on correct answers and reproduction of knowledge can use computer-marked assignments with a very large studentinstructor ratio (200:1 or more).

A graduate course on developing business strategies for IT companies where the participants are working in different companies will need a great deal of adaption and individualization to 
meet the different needs of a varied group of students, so may need a student-instructor ratio of 20:1.

A main driver of class size is the form of assessment. If students have to write even short essays three times during a course, the maximum ratio is likely to be $30: 1$.

All these figures assume that instructors have a fixed teaching load of so many hours a week. Contract instructors may handle larger numbers if they are paid per student, rather than a fixed weekly or monthly rate.

\section{Does online learning increase or decrease the workload of an instructor? To what extent?}

This depends entirely on how the course is designed. If instructors merely add technology on to their classroom teaching it will be more work. If they use technology to replace classroom teaching, you design the course around the time available for the instructor. Thus, if an instructor actually spends 100 hours delivering a classroom-based course, and the online course replaces the classroom based course, then the course would be designed to take 100 hours of the instructor's time. This though usually means hiring an instructional designer to help with the design.

Also, unlike classroom teaching, where the work is more or less the same each offering of the course, online courses require more time upfront in the first design of the course. Thus if an instructor has 100 hours per year, it may be necessary to take 100 hours in the first year for the design of the course, and design the course in such a way that it will require only 80 hours for delivery each year, so that over five years the instructor still works a total of 500 hours (but 180 the first year).

If course enrollments are higher than the instructor can manage at 80 hours a week, a contact instructor should also be hired to cover the extra students, paid for from the extra tuition fees.

In other words, online courses require a proper business plan and a course design that matches the time and resources available. Otherwise it will be more work.

\section{Do learners feel comfortable and confident about online learning experiences?}

That will depend on the design and to some extent the students' background and learning preferences. For most students, well-designed online courses work well (at the University of British Columbia the completion rate for online undergraduate courses is approximately $85 \%$, or $5 \%$ below the classroom-based completion rates for the same course). However, students studying online do need to be self-disciplined, meeting deadlines and working steadily over the course. Thus, immature students who are not used to taking responsibility for their own learning can struggle even with well designed courses.

However, independent learning is a skill that can be taught. Therefore, in a face-to-face class, students can gradually be introduced to online learning, for instance, initially working with three or four other students to do a joint online task then report back to the face-to-face class. Later they may be asked to do a whole task on their own, submit it online, and then have the work discussed in the face-to-face class. 
This suggests that online courses work best at the graduate and last year of an undergraduate program. However, this will depend on the classroom teaching being designed to encourage independent learning skills.

\section{Overall, is online learning a satisfying experience for instructors and learners?}

Yes, provided the course is well designed, and provided that there is plenty of opportunity for online interaction with an instructor and other students.

\section{Does online learning contribute more to 'open learning' or 'distance learning'?}

Online learning is more about 'distance' than 'open' learning. Only when $70 \%$ or more of the population have easy and cheap access to the Internet, can online learning really support open learning. There is a lot of confusion about 'open content', which in my mind is not really open learning. Open content merely means that the material is available over the Internet without cost to the user. Open learning though is more than just access to content; open learning has to remove other barriers, such as high cost, and provide learner support through a guide or mentor, and be embedded in a learning environment, so that there is context and meaning to the content.

\section{What are the most visible results of research on online learning?}

In general, research into online learning is very disappointing. There is not much good quality research. Most 'research' is about individual case studies with low numbers of students in the sample, making it difficult or impossible to generalize. Unfortunately, even in rich developed countries, research into online learning is not funded in such a way that it results in large, reliable studies, compared with research funding in other areas, such as medicine or social sciences.

Where research has been done well, it has tended to identify best practices in online learning, to show that online learning can be as good as, if not better, than face-to-face teaching, and to identify the factors that lead to effective teaching and learning online.

The main research challenge now is to identify for which students, and under which circumstances, online learning is best, and similarly where face-to-face instruction is best. There is almost no research on this topic, but it is a question that every instructor now needs to answer, if their teaching is to be as effective as possible.

\section{Does online learning replace traditional distance education practices?}

Absolutely. The main advantage of online learning over print/broadcast distance education is the opportunity for interaction between students and instructor, especially the instructor responsible for the content and the design of the course. The benefit is not just for the student, but also for the instructor, who has much better feedback about the teaching, and knowledge of the students. Thus, the quality of learning is taken to a much higher level with well-designed online learning, compared with well-designed print-based/broadcast distance education. 
This does not mean that there is no place for traditional distance education. Online learning depends on cheap and easy access to the Internet and computers. Where this does not exist and this is the case even today in many countries - then print/broadcast distance learning is much better than nothing.

\section{How do you see the future of online learning? Will it be more popular as a stand-alone application or be a part of blended learning systems?}

Eventually, I see courses or programs being designed so that students can take them in a variety of ways: entirely on campus, blended, or fully online, depending on their needs or circumstances. Thus, in the same class there will be students studying in a variety of ways.

However, this will be a long time coming, since it will require highly skilled instructors working with instructional designers to design, develop and deliver such courses. Unfortunately most instructors in higher education institutions currently do not have the skill or knowledge to do this. In the meantime, we will continue to see a differentiation between 'blended' and 'distance' online learning. The problem is that without fundamental redesign, blended learning, based on maintaining the classroom model with technology added on, does little to improve the quality of learning, but adds a great deal of cost. The real challenge will be to develop hybrid courses, where face-to-face time is reduced but not eliminated, so that students can get the best of both online and face-to-face learning.

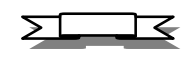

Although Professor Tony Bates was extremely busy during the period that we have conducted this interview, he was kind enough to find energy, spare time and answer our questions. He was very thoughtful, willing to share, and enlightening in his responses. We really appreciate his collaboration, frankness, understanding, and sense of responsibility that made this interview worth of reading for everybody in the field of educational technology.

Professor Bates emphasized that online learning has a great potential to revolutionize both formal and non-formal education if appropriate systems are in place. He indicated that careful instructional design is an important part of successful online learning along with well-trained instructors and state-of-the-art technologies. He has also pointed out that online learning has not been fully operative yet and still away from fulfilling its potential. Nevertheless, it has been making progress and gradually replacing traditional distance education by improving access and effectiveness of educational opportunities.

Correspondence: Ali Simsek, Professor, Institute of Communication Sciences, Anadolu University, Yunus Emre Campus, Eskisehir, Turkey 